\title{
INVESTIGATIONS ON SCOUR DEVELOPMENT AT TRIPOD FOUNDATIONS FOR OFFSHORE WIND TURBINES: MODELING AND APPLICATION
}

\author{
Arne Stahlmann ${ }^{1}$ and Torsten Schlurmann ${ }^{1}$
}

\begin{abstract}
Regarding offshore constructions, there is still a lack in knowledge of scour progression for complex structures like foundations for offshore wind energy converters at present, which is however necessary for its dimensioning. As an example of such complex structure types, Tripod foundations are constructed in German offshore wind farms at present. In order to describe physical processes and influencing factors on scour progression from a scientific point of view, comprehensive investigations on the scouring phenomena for Tripod foundations have been carried out and will be partly presented here. The overall investigation method consists of a combination of 1:40 small and 1:12 large scale physical model tests in wave flumes, numerical simulations using CFD methods and in-situ measured scour data. For the numerical modeling part, a sediment transport model formulation has been implemented into OpenFOAM software code. The results show a general variability of scour depending on the load boundary conditions and structural parameters. Scours occur both at the foundation piles and directly under the structure, which in this form could not be predicted using standard approaches, but which has to be taken into account when regarding the soil mechanical stability and the final dimensioning of the foundations.
\end{abstract}

Keywords: Tripod, Scour, Offshore Wind, Physical Modeling, Numerical Modeling, CFD

\section{INTRODUCTION \& OBJECTIVE}

Regarding foundations for offshore wind turbines (OWT) it is well known that in most cases scouring phenomena occur around the foundations, owing to the presence of the supporting structure and hence affecting changes in the natural flow regime at the sea bed around the foundation, leading to increased sediment mobility. As a step to further develop the share of renewable energies on the German electricity supply, numerous offshore wind farms will be constructed at the German coasts within the coming years. The starting signal for this development has been given by the construction of the first offshore test site alpha ventus in the North Sea, located $45 \mathrm{~km}$ off the coast of the Borkum Island. In water depths of about $30 \mathrm{~m}$, six (of the overall twelve) converters have been founded on Tripod structures (Figure 1). Due to the complexity of the Tripod foundation type investigated here, significant knowledge gaps in scour initiation and progression and its probable effects on the stability and usability of the structures are given, leading to lacking practical design guidelines. Therefore, such complex structures are generally constructed on a secure-based, but therefore partly cost-ineffective strategy. A main part of the overall costs for offshore wind turbines is given by the foundation, for which reason the choice of the foundation type, an accepted scour depth and a probable scour protection system have a high significance. Current design guidelines and appropriate literature give estimating values mainly for pile foundations, which however even differ in their results. Complex structures, which are geometrically different from pile foundations, are however not captured at all.
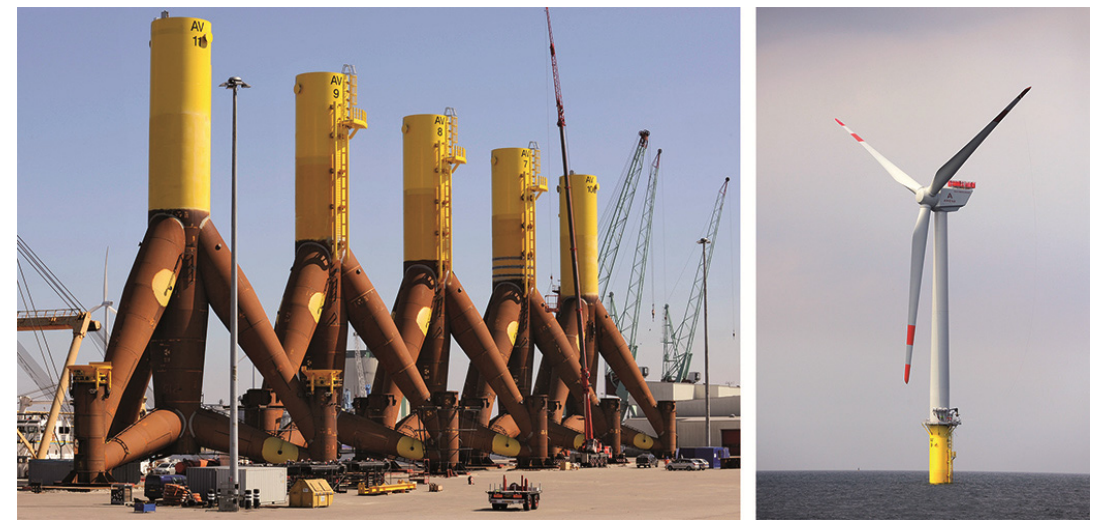

Figure 1. Tripod foundations for the alpha ventus test site. Source: Offshore-Stiftung/Multibrid and DOTI (2009).

\footnotetext{
${ }^{1}$ Franzius-Institute for Hydraulic, Waterways and Coastal Engineering, Leibniz Universität Hannover, Nienburger Straße 4, 30167 Hanover, Germany
} 
In recent decades, numerous studies have been carried out on scour at offshore structures, from which some empirical approaches on scour evolution have been identified, with main focus on cylindrical structures, e.g. Hoffmanns \& Verheij (1997), Sumer \& Fredsoe (2002), Zanke et al. (2011). Due to the complexity of the Tripod geometry, such approaches are nevertheless not directly applicable. The studies described here for example show significant scour depths underneath the central tube of the Tripod, which in this form could not be expected or calculated in advance using conventional approaches.

The main goal of research activities within the context of the investigations presented here is to gain deeper knowledge of scour evolution at complex OWT foundations in order to improve scour prediction and reduce uncertainties in the dimensioning that might allow more efficient foundation constructions in the future, going along with appropriate scour protection if necessary.

Within a sound research initiative, investigations on scour especially around the Tripod foundation have therefore been carried out. It consists of a unique combination of datasets from local scour monitoring in the alpha ventus test site, physical modeling as well as numerical modeling of the scour processes. Physical modeling has been carried out by means of 1:40 laboratory tests and 1:12 largescale model tests in the wave flume of the Franzius-Institute and the Large Wave Flume (GWK) in Hanover using model structures geometrically similar to the ones from the test site. The numerical simulations on scouring processes and sensitivity analyses have been carried out using OpenFOAM CFD code, by implementation of an appropriate sediment transport model formulation.

\section{HYDRAULIC MODEL TESTS \& FIELD DATA COLLECTION}

\section{Wave boundary conditions and soil parameters}

Sea state conditions for the alpha ventus test site can e.g. be determined from measurements at the research platform FINO1, which is located near the test field. In addition, extreme events on the basis of Hindcast modeling are supplied by DHI (2007). For the first investigation described here, boundary conditions for a 50-year extreme event have been chosen based on these data. In the course of the numerical modeling, however, recent extreme value analysis conducted on the basis of newer FINO1 data led to a modification of the sea state boundary conditions. According to DHI (2007), wave parameters for the 50-year extreme event result in $H_{s}=8.5 \mathrm{~m}, H_{\max }=15.8 \mathrm{~m}, T_{p}=12.3 \mathrm{~s}$ and $V_{\text {mean }}=1.3 \mathrm{~m} / \mathrm{s}$ for the tidal flow. Due to extreme storm events in 2006, 2007 and 2011, also in the study area, these values were however already exceeded several times. Including this new data base, values shown by recent calculations in Hansen (2011) therefore lead to $H_{s}=10.38 \mathrm{~m}$ and $T_{p} \approx 13.6 \mathrm{~s}$. Concerning the sediment parameters of the sea floor in the test field, measuring campaigns have shown that the sediment is mostly narrow distributed fine sand with a mean grain diameter $d_{50}$ of $0.2-0.25$ $\mathrm{mm}$.

\section{Physical modeling on 1:40 \& 1:12 scales}

To study the scouring phenomena and flow processes under wave conditions in principle, investigations have been carried out in laboratory experiments in the WKS wave flume on a model scale of 1:40. Therefore, a sandpit has been installed in the wave flume as illustrated in Figure 2, where OWT structures have been installed by a fixed (and rotatable) connection to the ground (Figure 3 ). Fine quartz sand with $d_{50}=0.15 \mathrm{~mm}$ has been used as model sediment. For more information on this subject, i.e. model setup and detailed results, we refer to Stahlmann \& Schlurmann (2010).

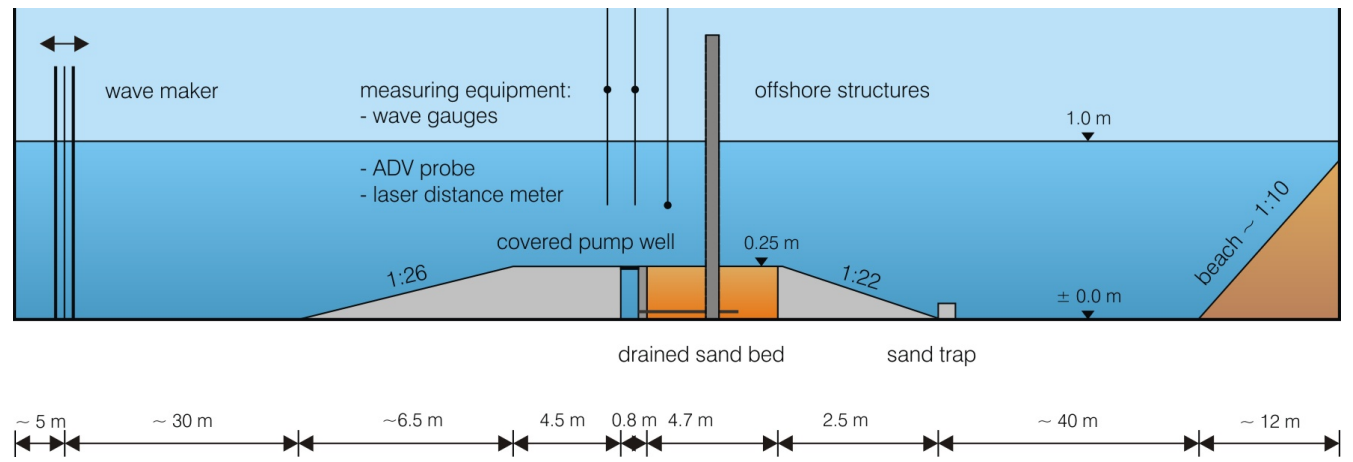

Figure 2. Sketch of the 1:40 physical model setup in the wave flume (cylinder installation; no scale) 

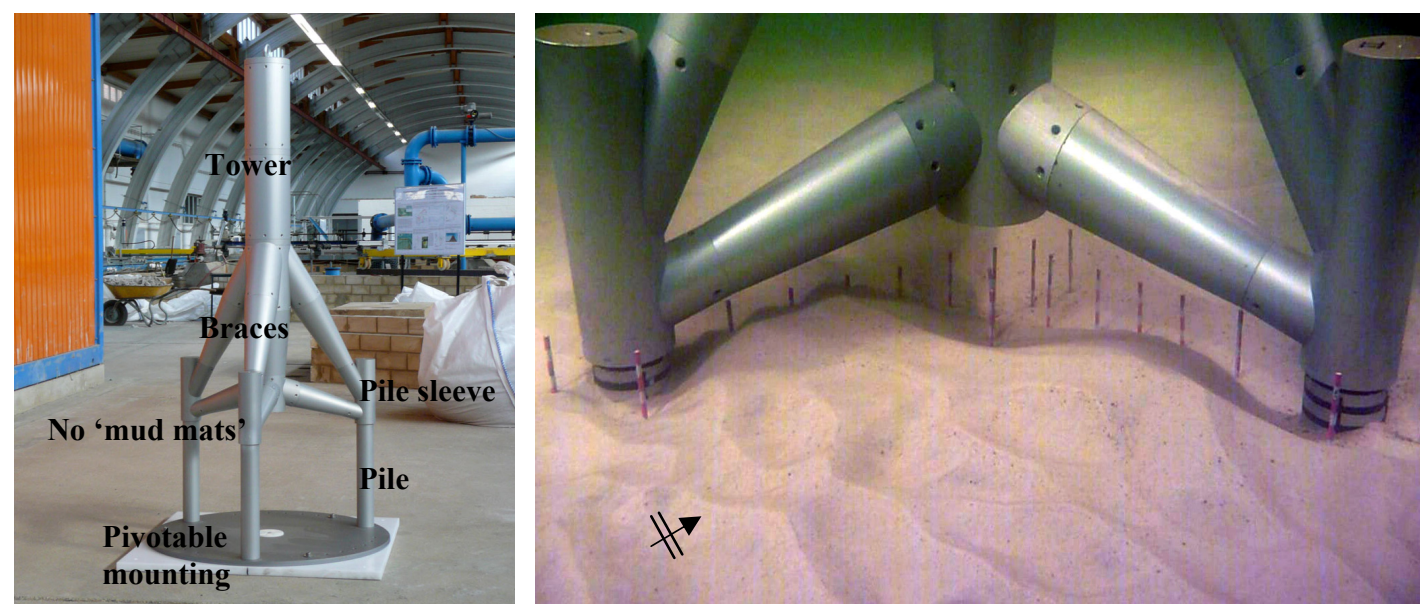

Figure 3. Left: 1:40 Tripod model with pivotable mounting. Right: Typical scour formation in a test series with regular waves after 7000 wave cycles (underwater picture).

For in-depth analysis of scour phenomena at the Tripod structure under minimized laboratory effects, 1:12 large-scale physical model tests have further been carried out in the Large Wave Flume (GWK) of the Coastal Research Centre (FZK) in Hanover, in combination with investigations on breaking wave effects, see Hildebrandt \& Schlurmann (2012). For the experiments, a sand bed (again fine sand, $d_{50}=0.15 \mathrm{~mm}$ ) has been installed in the GWK on a layer thickness of $1.2 \mathrm{~m}$ in the flume, overall similar to the procedure in the WKS flume. The Tripod model has been installed in the middle of the horizontal investigation area by a fixed connection to the channel floor. For the investigation of two flow directions of the foundation piles in relation to the main direction of wave attack, the model could be rotated in two positions around the vertical axis. In the following, $0^{\circ}$ describes the alignment position with one leg and $60^{\circ}$ the position with two legs facing the direction of wave attack, i.e. the piston type wave maker.

To study the flow pattern and scour development, the model was equipped with numerous measuring sensors: wave gauges, 1D propeller, 2D electromagnetic and 3D Nortek Vector and Vectrino+ ADV current probes were used for the recording of wave parameters and flow velocities/pattern in the immediate vicinity of the structure. To measure the temporal and spatial scour evolution, single beam echo sounders and underwater video cameras were used around and inside the foundation piles. Large-area scour development was measured after defined wave cycles during the tests by use of a multi beam echo sounder (Reson SeaBat) installed at a movable positioning platform above the flume. For a detailed description, we again refer to Stahlmann \& Schlurmann (2010) or Wilms et. al (2012), where a similar setup has been used.

As wave parameters, scaled boundary conditions with values given above were used, with $H_{m} / H_{s}=0.51$ to $0.77 \mathrm{~m}$ and $T_{m} / T_{p}=2.78$ to $5.52 \mathrm{~s}$, whereas the wave period has been increased in several test series to improve the visibility of the general scouring effects. Regular waves and JONSWAP wave spectra have been examined at a constant water depth of $d=2.5 \mathrm{~m}$. The maximum wave number of the overall twelve test series was 4000 waves per set, depending on the particular parameters, so that an almost-equilibrium scour development under design-relevant storm conditions was achieved. This corresponds to storm durations of up to 21 hours in nature. Exemplary results are given in Figure 4 for tests with regular waves (RW) and JONSWAP spectra, rotations of $0^{\circ}$ and $60^{\circ}$ after 3000 wave cycles. For selected measuring points at or below the structure, scour depths are given as relative values $S / D$ in the figures, with $D$ as the diameter of the piles. Due to the scaling number, natural ripple formations in the model are negligible here. 

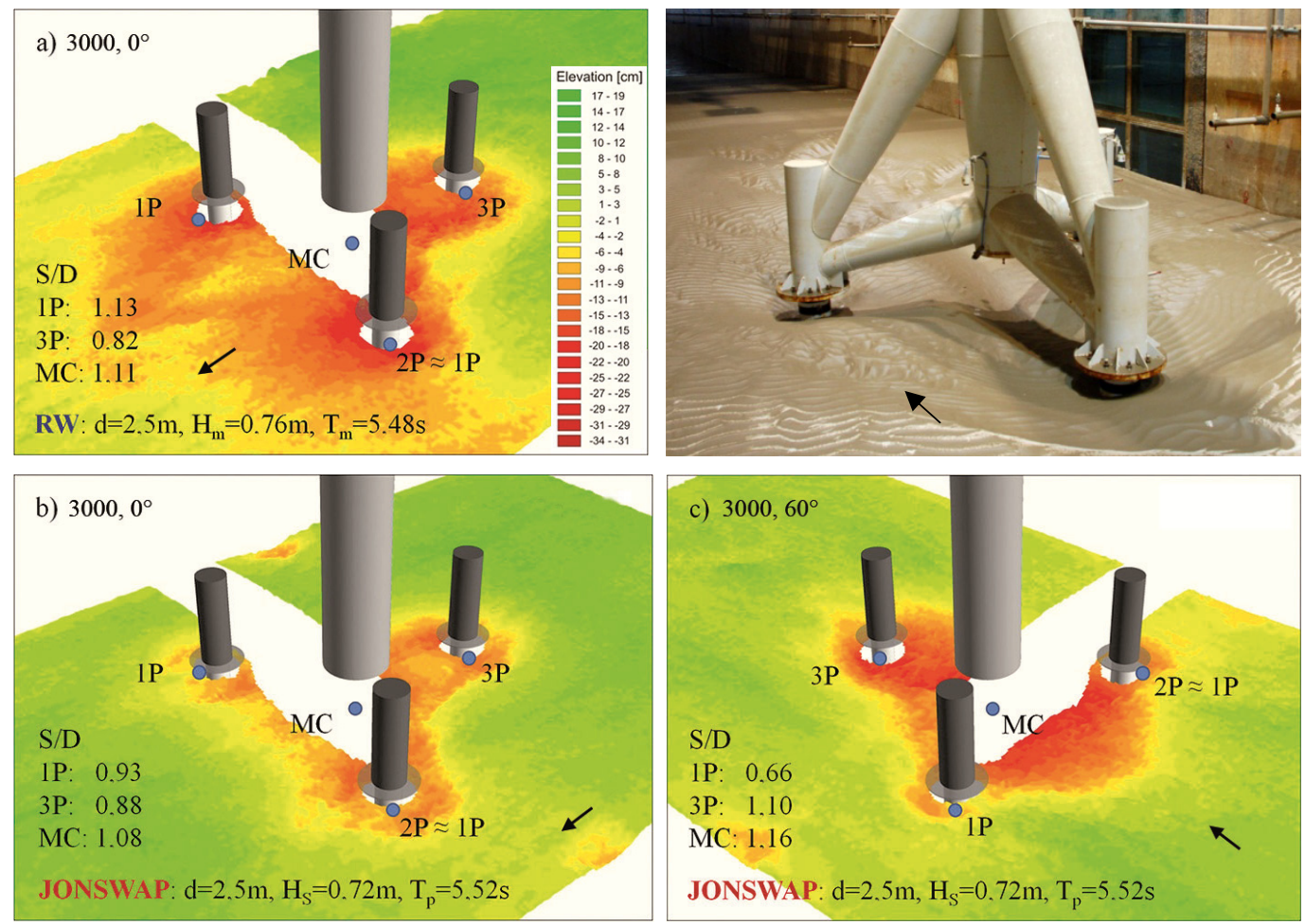

Figure 4. Scour pattern and rel. scour depths S/D for three test series after $\mathbf{3 0 0 0}$ wave cycles. Wave parameters and turning angles are depicted in the figures; Tripods are given symbolically.

From the tests it can generally be concluded that the characteristics including local and global scour evolution depend both on the rotational direction of the structure and the load conditions. Local scour depths at the piles in the area behind the structure are slightly higher than in the front. Regular waves lead to relatively higher sediment mobility around the structure compared to the investigated JONSWAP spectra when using similar wave parameter values. However, scour depths at the piles and below the structure are in a comparable range. It can overall be noted that due to the complexity of the Tripod structure, scour does not only occur at the foundation piles alone as it is known for pure pile foundations (monopiles), but also in the immediate vicinity and below the structure (central tube). In the latter case, scour depths can reach much higher values than measured at the foundation piles.

\section{Scour measurement in the test site}

As part of the research initiative RAVE (Research at Alpha Ventus) supported by the German Federal Ministry for the Environment (BMU), scour measurements at the Tripod structure M7 in the alpha ventus test site were conducted by the German Federal Maritime and Hydrographic Agency (BSH). The collection was carried out by use of single beam echo sounders installed at the foundation piles and underneath the central tube, measuring in few-minutes intervals, as well as by measuring campaigns using ship-based multi-beam echo sounder collections of the surrounding sea floor in the vicinity of the structure. Figure 5 gives an impression of the in-situ detected scours at the M7 Tripod, dated April 2010. The maximum measured scour depths at the foundation piles (water depth approximately $30 \mathrm{~m}$ here) take values between 2.5 and $3.3 \mathrm{~m}$ and 5.5 to $5.8 \mathrm{~m}$ below the central tube. The measured scours, expected to be at a temporary equilibrium stage at the time of admission, had however further deepened, so that at date of February 2012, scour depths had reached depths of around 2.6 to $3.6 \mathrm{~m}$ at the piles and $6.8 \mathrm{~m}$ below the central tube. Using the classical relative scour depth $S / D$ measure, this leads to values of 1.1 to 1.6 and 3.0, with $D$ as the diameter of the piles. When however changing $D$ for the latter value to the diameter of the lowermost (not ground-affiliated) central tube segment with $4.5 \mathrm{~m}$ instead, the relative scour depth $S / D$ would then be given by a value of 1.5 here. 


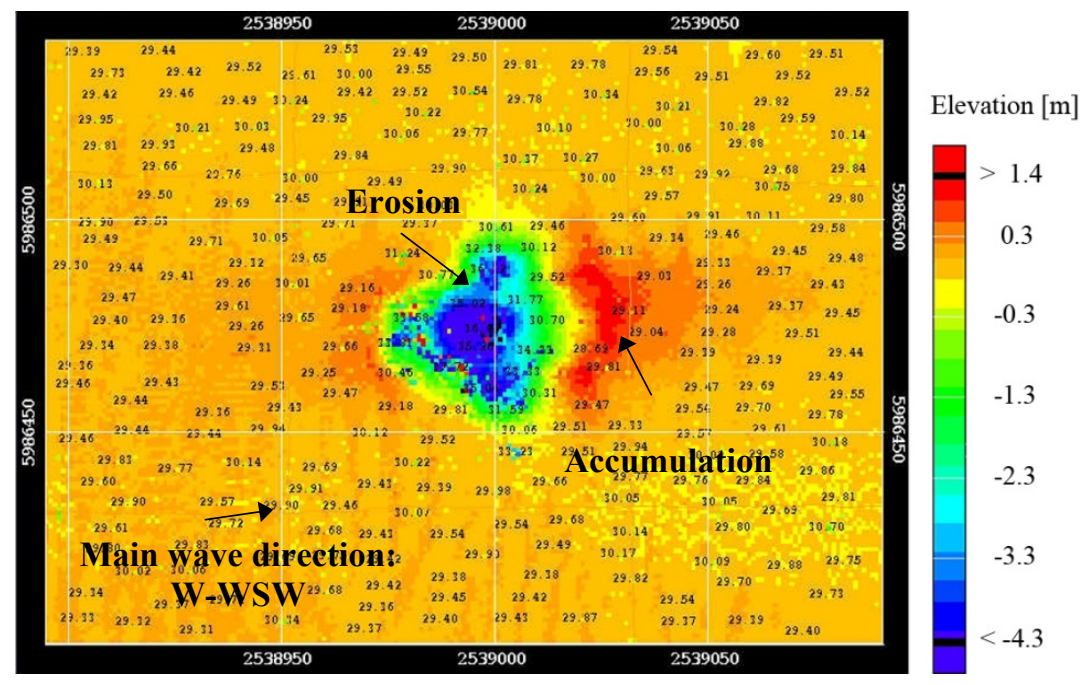

Figure 5. Multi beam Survey at M7 Tripod in the alpha ventus test site. Record from April 2010 given as 1x1m grid values. Original source: Lambers-Huesmann \& Zeiler, BSH 2010.

A comparison with scour depths from the physical model show at least a qualitatively, overall good agreement between model results and nature, so that local and global scour developments with erosion and accumulation areas could be reproduced in sufficient quality. Nevertheless, relative scour depths in the model give lower absolute values, especially in the area below the central tube. The reasons for this are some inevitable simplifications in the model experiments, in particular in relation to the sea state conditions, i.e. real conditions including tidal flow were modeled as a unidirectional wave load in the wave flume, as well as general laboratory and scaling effects (sediment, wall boundaries).

\section{NUMERICAL INVESTIGATIONS}

\section{Model description}

In order to investigate the combined impact of waves and (tidal) current flow amongst others, model studies have been carried using numerical CFD methods. The tests were performed within the framework of the open source software code OpenFOAM ${ }^{\circledR}$ (OpenCFD Ltd.), whereas the Volume of Fluid Method (VOF) is used to capture the free surface. Further information on the specific implementations can e.g. be found in Jasak (1996). For the present investigations, the approach of solving the Reynolds-averaged Navier-Stokes equations (RANS) is applied in combination with the k$\omega$ SST turbulence model after Menter (2003).

Using this model, investigations on flow pattern, turbulences and resulting bottom shear stresses in the region of the Tripod foundation over a fixed bed were conducted on the one hand, further described in the following. On the other hand, a sediment transport model including suspended load and bed load transport formulations has been implemented, which was used to calculate spatial scour development or, generally said, sediment transport including erosion, transportation and sedimentation processes, which is further described later. The bed evolution has been modeled on the basis of a vertically changing bed boundary grid and inner nodes of the computational domain, i.e. a moving mesh approach. The overall knowledge gained here can be used to locate areas of potential risk for scour development around the structure or to optimize a scour protection design. Furthermore, parameter studies with varying boundary conditions and structural parameters can be conducted in order to investigate and quantify their direct influences on scour progression.

\section{Model setup and boundary conditions, rigid bed}

The calculations were primarily conducted on a scale of $1: 40$, which is the model scale of the laboratory wave flume experiments. In the rigid bed simulations, the model area comprises a range of about $7^{*} D$ in width and $23^{*} D$ in length, at a distance of $6^{*} D$ from the inlet to the vertical axis of the Tripod structure, with $D$ being the overall diameter of the structure, using an overall number of around one million cells. Regarding the spatial grid resolution, the mesh consists of a multi-level grid: In areas without structural influence, the grid cells (block mesh) have a resolution of mainly $5 \mathrm{~cm}$ in horizontal 
$(\mathrm{x}, \mathrm{y})$ direction. In vertical $(\mathrm{z})$ direction, the grid is resolved with $5 \mathrm{~cm}$ in the middle part of the water column, $1 \mathrm{~cm}$ in the area of wave amplitude and a vertically graded mesh at the bottom boundary with lowermost cells in the range of $y^{+}=\sim 1-25$. In the near-field of the structure, grid cells are then gradually refined by splitting each computational cell by factor of 1-4 in all directions, giving a main resolution of $0.6 \mathrm{~cm}$ around the main structure and $0.2 \mathrm{~cm}$ at the piles, whereas the vertical resolution of the lowermost cells at the bottom boundary was kept with above given $y^{+}$range.

Regarding the model boundary conditions at the inlet, regular waves using Stokes $2^{\text {nd }}$ order theory were used as input by prescribing surface elevation and velocity components as well as a logarithmic current profile for the flow directly at the boundary. For the combined input, velocity components were superimposed linearly. In the standard implementation, OpenFOAM does not have a transmissive outlet boundary condition for surface waves, which results in partial reflections at the outlet boundary. For this reason, a wave damping technique has been implemented using a blend between computed and target values, which effectively eliminates parasitic reflections in the study area. The Tripod model itself has been regarded as hydraulically smooth, same for the lower (bottom) model boundary. Bottom shear stresses were computed by use of the Reynolds stress tensor from the turbulence quantities.

In the present numerical model setup, natural sea state boundary conditions were controlled by means of representative regular wave trains. By evaluating the physical model WKS and GWK test series with regular waves and wave spectra, the best quantitative agreement in relation to comparable scour depths so far was found to be $H_{m} \approx 0.9^{*} H_{s}$ and $T_{m} \approx 0.9^{*} T_{p}$, which is also within the estimates given Sumer (2002) and Göthel (2008). The wave and current boundary conditions given above therefore lead to values of $H_{m, 50}=0.234 \mathrm{~m}, T_{m, 50}=1.94 \mathrm{~s}$ and $v_{\text {mean }}=0.206 \mathrm{~m} / \mathrm{s}$. The water level was kept constant at $0.75 \mathrm{~m}$. The critical shear stress for the initiation of motion for the sediment investigated here results in $0.141 \mathrm{~N} / \mathrm{m}^{2}$, calculated using the parametric approach given in Soulsby (1997).

The magnitudes of bed shear stresses in the undisturbed case were determined from the numerical model, given as approx. $0.08 \mathrm{~N} / \mathrm{m}^{2}$ for tidal flow, $0.53 \mathrm{~N} / \mathrm{m}^{2}$ for the maximum value under the wave crest for waves and $0.61 \mathrm{~N} / \mathrm{m}^{2}$ for the combined load case (wave crest). It can already be seen that even in the undisturbed case, resulting shear stresses under waves due to an extreme event are almost by a factor of seven higher than under (tidal) current flow.

\section{Rigid bed simulations and results}

Figure 6 gives the bed shear stresses for current load, waves and combined load under structural influence, for the rotational direction of $0^{\circ}$ in a section of the numerical model. The color bars have been adapted to the respective cases and therefore maximum values (red) cover larger spans, which however occur only very locally limited in each case. White areas indicate the positions of the piles.

Under pure current flow (a) shear stresses locally increase by a factor of up to 12 due to the presence of the structure compared to the undisturbed case $\left(0.08 \mathrm{~N} / \mathrm{m}^{2}\right)$, whereas largest values occur at the sides of the rear piles and below the lower braces due to the concentration of the flow field. Beneath the center tube, shear stresses are still increased by a factor of 2-2.5, whereas shadowing effects lead to reduced shear stresses behind the rear piles.

Under wave load (b) the maximum bottom shear stresses also occur at the sides of the piles and below the lower braces, with locally increased values of up to a factor of 8.5 compared to the undisturbed case $\left(0.53 \mathrm{~N} / \mathrm{m}^{2}\right)$. The overall stress distribution is similar to the one under current conditions at the time of passing wave crest. The influencing area of the structure is however substantially smaller than under constant flow due to changing flow direction under waves, which leads to a local (temporal) limitation of the increased shear stresses. Due to generally increased flow velocities under extreme conditions, bottom shear stresses are overall larger than under considered current flow, with values up to $4.5 \mathrm{~N} / \mathrm{m}^{2}$ at the piles and $0.5 \mathrm{~N} / \mathrm{m}^{2}$ underneath the central tube. For the shear stress distribution in the case of a wave trough (not shown here) and thus an opposite direction of flow below the structure, a similar picture of the (absolute) stress distribution is given. Due to the wave asymmetry, values are nevertheless slightly lower than compared to the wave crest passage.

Under combined load (c) the constant current flow obviously leads to an increase in flow velocities and bottom shear stress compared to pure wave load. Maximum values occur at the piles due to constriction and acceleration effects, reaching values of up to $5.5 \mathrm{~N} / \mathrm{m}^{2}$ and are therefore approximately 9-fold increased. Typical constant-flow phenomena such as periodic vortex shedding at the structure cannot be found here. Below the center tube, the shear stress rises up to $1 \mathrm{~N} / \mathrm{m}^{2}$ and is therefore higher than compared to a linear addition of the individual load components. This effect 
increases with reduced distance in the direction of the piles below the braces, where values of $2 \mathrm{~N} / \mathrm{m}^{2}$ are measured.
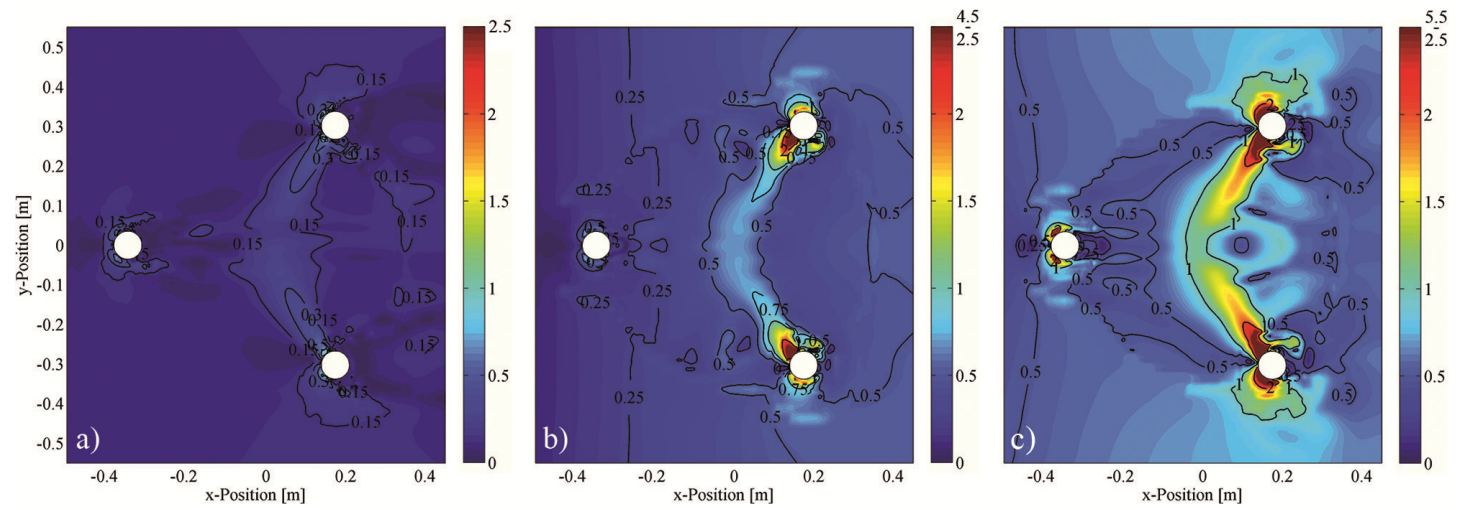

Figure 6. Bed shear stresses in the near-field of the Tripod under a) current load, b) waves, c) combination. Turning angle $0^{\circ}$. Flow direction from left to right. (Stahlmann \& Schlurmann, 2012)

Figure 7 gives amplification factors $\alpha$ of the bottom shear stresses, which indicates the ratio of the local bed shear stresses to the shear stress without the presence of a structure, for the cases of $0^{\circ}, 30^{\circ}$ and $60^{\circ}$ under the combined load case of waves and current flow. For $0^{\circ}$ and $60^{\circ}$, zones of increased bed shear stress are similar, with maximum values at the two piles lying orthogonal to the load direction and below the braces. At $0^{\circ}$ inflow direction, values behind the central tube, between the rear piles, are higher due to the superposition of the individual flow directions. For the $30^{\circ}$ approach flow, maximum load occurs at the exposed, individual pile. Overall, the values of bottom shear stresses are however in the same orders of magnitude for all cases.
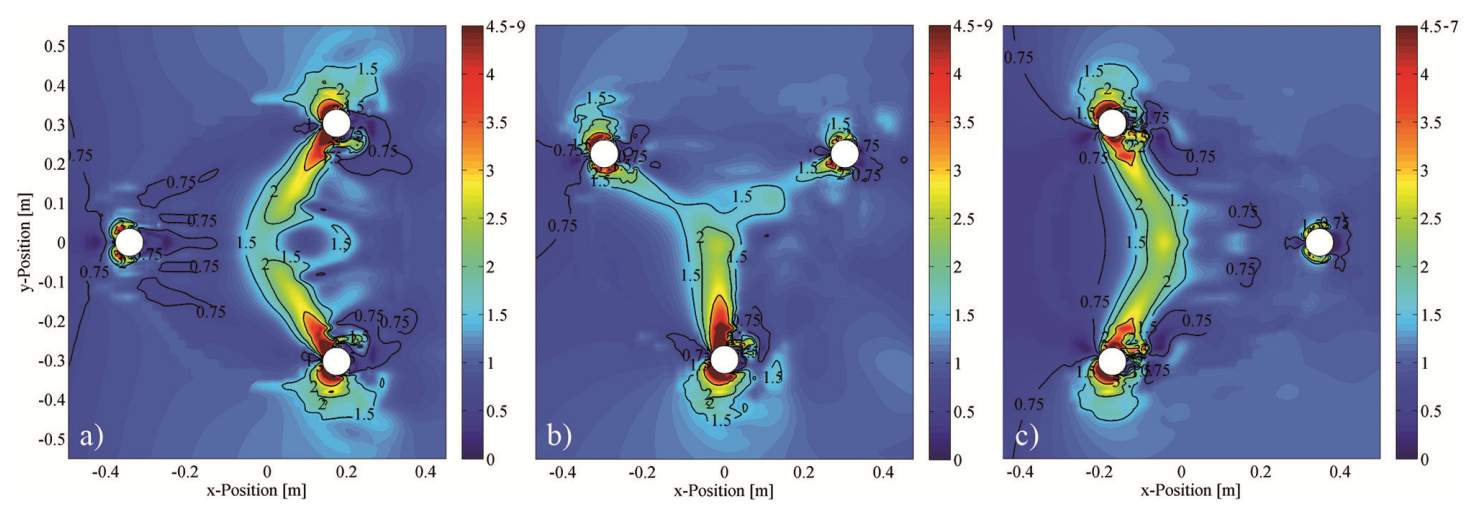

Figure 7. Distribution of bed shear stress amplification factors $\alpha$ in the near-field of the Tripod under combined wave and current load for turning angles a) $0^{\circ}$, b) $30^{\circ}$, c) $60^{\circ}$. Flow direction from left to right. (Stahlmann \& Schlurmann, 2012)

\section{Scour simulations and results}

The implemented scour or sediment transport model comprises both bed load and suspended load. For the results presented here, the bed transport fluxes $q_{b}$ have been modeled using the approach of Engelund \& Fredsøe (1976). The transport formulation for each computational face on the bottom boundary grid has been implemented in vectorial form, generally based on the idea given in Kovacs \& Parker (1994), including slope-dependent modifications of the resulting shear stresses. The overall approach is thereby similar to that used in Roulund et al. (2005) and Jacobsen (2011). To account for the steep-slope mechanisms, a sediment sliding procedure has further been incorporated.

The suspended load has been modeled solving a passive scalar advection-diffusion transport equation including input/output to and from the water column due to erosion/deposition as a source term in the lowermost computational cells above the bed boundary. As suspended entrainment model, 
the approach of Engelund \& Fredsøe (1976) and Fredsøe \& Deigaard (1992) has been applied, which is giving the reference concentration $c_{b}$ slightly above the bed boundary. Following e.g. Garcia (1999), the entrainment flux $E$ has then been modeled as $c_{b}$ times the sediment settling velocity in upward direction. In the reverse direction, the deposition flux $D$ has been modeled as local concentration $c$ times the local settling velocity, whereas $c$ has been taken from the lowermost computational cells above the bed boundary here. The bed evolution changes in vertical direction have been calculated solving the Exner equation by incorporating the fluxes $q_{b}, D$ and $E$ as well as the bed porosity on the 2D bottom boundary grid (FAM). Results have then finally been mapped back to the 3D fluid domain (FVM) in order to prescribe vertical mesh motion of both bottom grid and inner nodes.

Different from the rigid bed simulations given above, the bottom shear stress is calculated using the van Driest (1956) velocity profile here, with coordinate shift to account for surface roughness. Wave and current boundary conditions as well as wave absorption in the outlet zone (see Figure 8) have been modeled by use of a wave generation toolbox within OpenFOAM, further described in Jacobsen et al. (in print). The model area comprises a range of about $4^{*} D$ in width and $16^{*} D$ in length, with a distance of $6^{*} D$ from the inlet boundary domain to the vertical axis of the Tripod structure, using an overall number of around 0.54 million cells. Regular waves using Stokes $2^{\text {nd }}$ order theory were used as load input by prescribing surface elevation and velocity components as well as a logarithmic current profile for the flow in the wave generation zone at the inlet. For the combined load input, velocity components were again superimposed linearly.

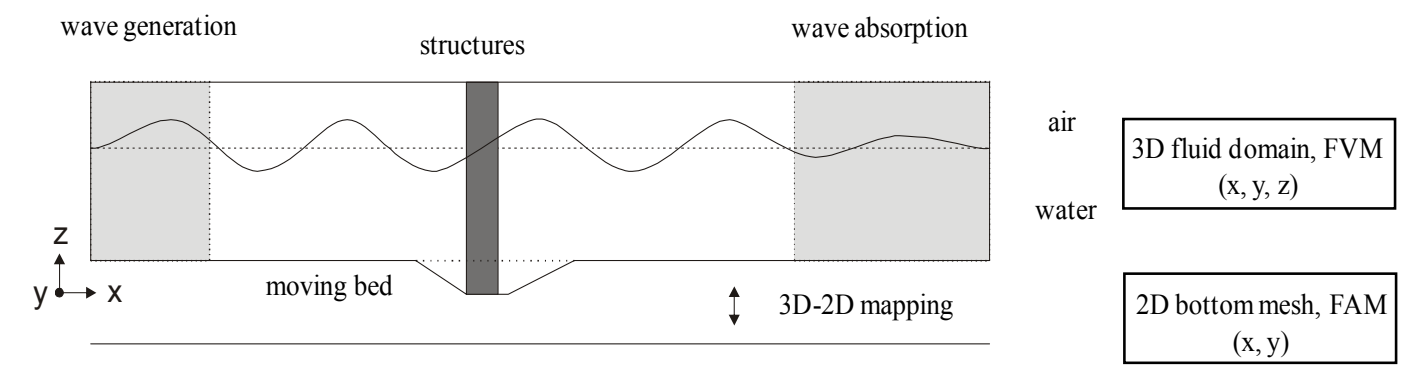

Figure 8. General sketch of the numerical model setup in the scour calculations

Due to vast computational times necessary for scour simulations esp. around (complex) objects, a weak coupling between hydrodynamic flow model and sediment transport calculations is performed here in the following manner: (1.) for a time span equal to the wave period, the hydrodynamic quantities and the suspended load transport are calculated and stored for fragments of the wave period; (2.) afterwards, the bed load sediment transport is calculated, the Exner equation is solved and (3.) the mesh movement algorithm is applied for every single time fragment over the entire wave period. As local bed changes between the single wave cycles are typically rather small, the calculations in (2.) and (3.) are carried out several times using the pre-calculated hydrodynamic quantities from (1.), whereas the number of such 'repeating loops' has been chosen as 10 here, i.e. the hydrodynamic quantities after mesh movement are updated every 10 wave cycles.

In the following, results of numerical scour simulations are given for two of the above described cases in the rigid bed calculations on shear stresses: (i) the extreme event wave load case given in Figure $6 \mathrm{~b}$ ) and (ii) the combined wave-current load given in Figure $6 \mathrm{c}$ ), after duration of 250 wave cycles. Although these scour developments obviously will not represent equilibrium scour stages, the load differences and general resulting scour pattern are however demonstrated well.

In the case of wave load (wave direction from left to right) in Figure 9 a) with $d=0.75 \mathrm{~m}$, $H_{m}=0.234 \mathrm{~m}$ and $T_{m}=1.94 \mathrm{~s}$, local scour start to form mainly around the piles of the structure, under the braces and under the center tube. This scour pattern therefore corresponds well with the areas of high shear stresses from the rigid bed calculations, as well as with the experience in the physical model tests. Due to the reduced wave period compared to the laboratory tests given above (1.94s vs. 3.0s in the WKS flume), the scour development is however less pronounced here. Regarding the shear stress distribution in Figure 6 b), which is given as a snapshot at the time of passing wave crest, one might 
expect even higher local scours around the piles. This is however not given in the overall scour simulations, as local shear stresses at the piles rapidly decrease with increasing scour depths on the one hand and local scour holes are partly refilled with reverse flow direction, i.e. passing wave trough on the other hand. At the time of 250 wave cycles given, local relative scour depths $S / D$ reach values of 0.51 at the pile and 0.77 in the area under the central tube, with $D$ being the diameter of the piles here. The scour development so far stays locally limited to the very near-field of the structure, with the exception of an area of accumulation behind the structure.

It generally has to be noted that the absence of ripples in the simulations in the far-field of the structure mainly results from the expanded grid cells in these regions.
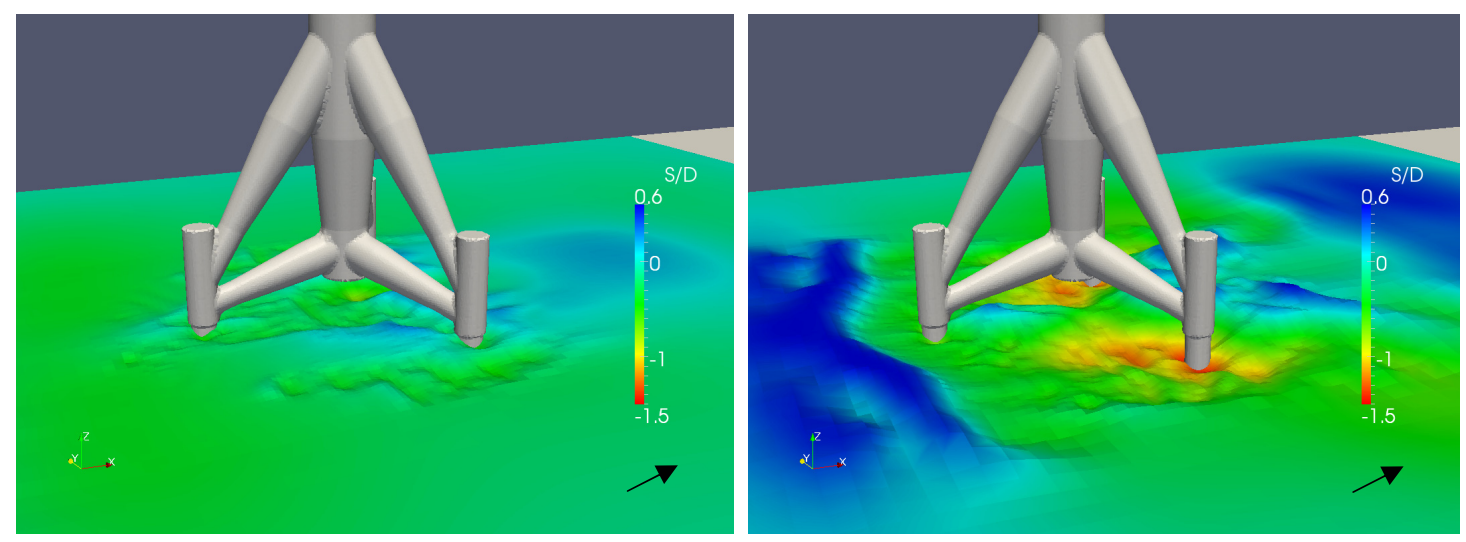

Figure 9. Scour development after 250 wave cycles in the numerical model, a) wave load conditions, b) wave + current load conditions. Flow direction from left to right.

In Figure $9 \mathrm{~b}$ ), results for the simulation of the combined wave and current load case with $d=0.75 \mathrm{~m}, H_{m}=0.234 \mathrm{~m}, T_{m}=1.94 \mathrm{~s}$ and $v_{\text {mean }}=0.206 \mathrm{~m} / \mathrm{s}$ are given after a period of 250 wave cycles. In the simulation, the direction and magnitude of the superimposed current was kept constant in the direction of wave propagation, i.e. no periodic flow reversal was modeled here.

In direct comparison with the pure wave load case, some differences may be observed, whereas it can generally be stated that the sediment transport capacity is much higher in the combined case. This is stemming from the fact that the near-bed flow velocities and therefore resulting bed shear stresses are higher in case of aligned flow directions, with values even higher than resulting from linear superposition of the single load case results. Compared to the times of local flow stagnation under pure wave conditions due to change of the orbital motion directions, local current flow components are still present here, further transporting sediment away. As the transport potential in the following, reversal flow direction is damped (again compared to pure wave load) due to the additional current flow, this additionally results in less local backfilling.

At the time of 250 wave cycles given above, the local relative scour depths $S / D$ in this case reach values of 1.42 at the rear piles and 0.77 at the front pile, as well as 0.53 under the central tube, with $D$ again being the diameter of the piles here. The global sediment transport does not stay that locally limited, as overall more sediment is transported away from the near-field of the structure. This esp. results in a larger accumulation area in the rear part of the Tripod, both in the far-field and directly behind the Tripod structure. The accumulation in the front part mainly results from sediment being picked up farer in the upstream part of the structure, but also from sediment erosion around the structure at reverse flow due to wave motion, which is then deposited at the time of flow stagnation.

From the present investigations it cannot be fully explained why local scours in both nature and physical models under pure wave conditions (with increased wave periods), although even less pronounced here, are largest under the center tube, compared to the results for combined wave-current load. It can however be assumed that this results from more complex interactions between the load components, its magnitudes and changing directions, than it has so far been modeled here, which is therefore under current investigation. 


\section{CONCLUSIONS AND OUTLOOK}

The investigations on scour development by use of physical and numerical modeling carried out here have shown that the local formation and evolution of scour at Tripod OWT foundations is strongly influenced by the boundary condition parameters, i.e. waves and (tidal) current flow as well as the orientation of the structure. Scour does not only occur directly at the foundation piles, but also in the near-field, partly with largest scour depths below the structure in case of wave load. For the combined current-wave load case with aligned flow direction given here, modeled scour depths have however been found to be largest at the rear foundation piles. For the examined cases, the load combination of current flow and an extreme storm event form the design case results in bottom shear stresses at the structure that are generally higher than calculated by a linear addition of the individual components. During these events, the waves lead to locally strongly increased bottom shear stresses and a remobilization of sediment, whereas an accelerated transport and removal of sediment is carried out by the additional current flow mainly in the direction of the current.

\section{ACKNOWLEGMENTS}

The authors gratefully acknowledge the support of the German Federal Environment Ministry (BMU) within the funded project "Ganzheitliches Dimensionierungskonzept für OWEATragstrukturen hinsichtlich Lasten, Langlebigkeit, Gründung und Gesamtstruktur (GIGAWIND alpha ventus - LUH)" (BMU code 0325032). Project details can be collected from www.gigawind.de.

\section{REFERENCES}

DHI. 2007. Borkum West - Hydrographische Standortbedingungen. Modellierung und Statistische Analyse. Syke.

van Driest, E.R. 1956. On turbulent flow near a wall. J. Aeronaut. Sci. 23, 1007-1011, 1036.

Engelund \& Fredsøe. 1976. Sediment Transport Model for Straight Alluvial Channels. Nordic Hydrology, 7(5):293-306.

Fredsøe, J., Deigaard, R. 1992. Mechanics of Coastal Sediment Transport. Advanced Series on Ocean Engineering - Volume 3. World Scientific.

Garcia, M.H. 1999. Sedimentation and Erosion Hydraulics. Hydraulic Design Handbook, Chapter 6, Larry Mays, ed., McGraw-Hill, Inc.

Göthel, O. 2008. Numerical modeling of flow and wave induced scour around vertical circular piles. Institut für Strömungsmechanik und Elektronisches Rechnen im Bauwesen der Leibniz Universität Hannover, Bericht 76/2008, Hanover.

Hansen, M. et al. 2011. Probabilistic Safety Assessment of Offshore Wind Turbines. Annual Report 2010, Hanover.

Hildebrandt, A., Schlurmann, T. 2012. Breaking Wave Kinematics, local Pressures and Forces on a Tripod Support Structure, Proceedings of the Coastal Engineering Conference, No. 33, Santander.

Hoffmans, G.J.M.C., Verheij, H.J. 1997. Scour Manual. Balkema, Rotterdam.

Jacobsen, N.G., Fredsøe, J. 2011. A Full Hydro- and Morphodynamic Description of Breaker Bar Development. Ph.D. thesis, Department of Mechanical Engineering, Technical University of Denmark.

Jacobsen, N.G., Fuhrmann, D.R., Fredsøe, J. (in print). A Wave Generation Toolbox for the OpenSource CFD Library: OpenFoam. Int. J. Numerl. Meth. Fluids.

Jasak, H. 1996. Error Analysis and Estimation for the Finite Volume Method with Application to Fluid Flows. Ph.D. thesis, Imperial College of Science, Technology and Medicine. London.

Kovacs, A., Parker, G. 1994. A New Vectorial Bedload Formulation and Its Application to the Time Evolution of Straight River Channels. Journal of Fluid Mechanics, 267:153-183.

Menter, F. 2003. The SST Turbulence Model with Improved Wall Treatment for Heat Transfer Predictions in Gas Turbines. Proceedings of the International Gas Turbine Congress (2003). Tokyo: November 2-7.

Roulund, A., Sumer, B.M., Fredsøe, J. 2005. Numerical and experimental investigation of flow and scour around a circular pile. Journal of Fluid Mechanics, 534:351-401.

Soulsby, R.L. 1997. Dynamics of marine sands. Thomas Telford Ltd. London.

Stahlmann, A., Schlurmann, T. 2010. Physical Modeling of Scour around Tripod Foundation Structures for Offshore Wind Energy Converters, Proceedings of the Coastal Engineering Conference, No. 32, Shanghai. 
Stahlmann, A., Schlurmann, T. 2012. Investigations on Scour at Tripod Foundations [Kolkbildung an komplexen Gründungsstrukturen für Offshore-Windenergieanlagen: Untersuchungen zu TripodGründungen in der Nordsee]. Bautechnik 89(5):293-300.

Sumer, B.M., Fredsøe, J. 2002. The Mechanics of Scour in the Marine Environment. World Scientific Publishing Co. Pte. Ltd.

Wilms, M., Stahlmann, A., Schlurmann, T. 2012. Investigations on Scour Development around a Gravity Foundation for Offshore Wind Turbines, Proceedings of the Coastal Engineering Conference, No. 33, Santander.

Zanke, U.C.E., Hsu, T.-W., Roland, A., Link, O., Diab, R. 2011. Equilibrium scour depths around piles in noncohesive sediments under currents and waves. Coastal Engineering, Vol. 58, 986-991. 